\title{
Identifying Predictors of Emergency Room Utilization in Primary Care
}

\author{
Lisa Renee Miller-Matero, $P h D^{1,2,3}$, Joseph Patrick Coleman, $P h D^{1,2,3}$, Ramon Aragon, $\mathrm{MD}^{7}$, and \\ Jeffrey Yanez, $M D^{2}$
}

'Department of Behavioral Health, Henry Ford Health System, Detroit, USA; ${ }^{2}$ Department of Internal Medicine, Henry Ford Health System, Detroit, USA; ${ }^{3}$ Center for Health Policy and Health Services Research, Henry Ford Health System, Detroit, USA.

KEY WORDS: primary care; emergency medicine; utilization.

J Gen Intern Med 33(10): 1629-30

DOI: $10.1007 / \mathrm{s} 11606-018-4529-0$

(C) Society of General Internal Medicine 2018

\section{INTRODUCTION}

Emergency room (ER) utilization is a growing, costly concern for health care in the USA. Several variables have been reported as contributing factors to increased ER utilization including chronic health conditions, depression, lower cognitive abilities, and socioeconomic status. ${ }^{1}$ However, no prior research has simultaneously analyzed these patient-specific variables. Additionally, most of the research that has identified factors related to ER utilization has been conducted after patients have already sought ER services. To decrease ER use, it is important to identify patients before they visit the ER. With the growth of behavioral health services availability in primary care clinics, early identification of patients at risk for utilization of ER services may be possible. The purpose of this study was to determine whether predictors of ER utilization could be identified during a behavioral health consultation in the primary care setting and to investigate which variables were most important in predicting higher ER use.

\section{METHODS}

This project was part of a larger study that examined predictors of health care utilization. ${ }^{2}$ Retrospective medical record reviews were completed on 147 patients who met with an integrated psychologist in an Academic Internal Medicine Clinic between September 2013 and February 2014. Variables collected from charts are reported in Table 1 and included demographics as well as the number of ER visits and the rate of all missed appointments across the health care system during a 2-year period. Information from the behavioral health evaluation included cognitive functioning (Montreal Cognitive Assessment, MoCA), healthrelated reading grade ability (Rapid Estimate of Adult Literacy in Medicine, REALM), ${ }^{4}$ health numeracy (Brief Medical Numbers Test, BMNT), and depression and anxiety

Published online June 8, 2018 symptoms (Hospital Anxiety and Depression Scale, HADS). ${ }^{6}$ Suggested cut-off values from each of these measures were used to group patients into categories for each variable. We entered variables statistically significant on univariate analysis into a multivariate linear regression model (SPSS V. 24). This study was approved by our IRB.

\section{RESULTS}

The patient demographics were the same as reported previously. ${ }^{2}$ Sixty-four patients $(43.5 \%)$ had at least one ER visit during the study time period (range 1-10). Univariate predictors of increased ER visits included inadequate health numeracy, probable depression, impaired cognitive functioning, having government insurance, fewer years of education, a lower household income, and a higher number of missed appointments (Table 1). Independent predictive variables included having a lower income, frequent missed appointments, and government insurance (Table 2, $\left.F=6.12, p<.001, R^{2}=0.31\right)$.

\section{DISCUSSION}

Our findings should be interpreted with caution, since they are based on a relatively small sample in a singlesite; our models need to be corroborated in other settings and in a larger sample. However, our findings from this study suggest that predictors of emergency room use can be identified in primary care. In our sample, having government insurance and missing appointments may be more important than other factors (i.e., chronic health conditions, psychiatric symptoms, and cognitive factors) in predicting ER visits. If true, this suggests that patients who are experiencing barriers to seeking outpatient care may be at risk for higher ER use. Patients could be missing appointments due to difficulties with accessing outpatient care (i.e., transportation, co-pays, inconvenient appointment times) or lack the motivation or understanding of the need for attending appointments (i.e., depression, low health literacy). ${ }^{2}$ Once patients miss appointments, they may have a need for more emergent care. Alternatively, these patients may not need emergent care, but may view the ER as a more convenient option. 
Table 1 The Relationship of Emergency Room Visits and Demographics, Psychiatric Symptoms, Cognitive Impairment, and Literacy

\begin{tabular}{|c|c|c|}
\hline Continuous variables & $r$ & $p$ \\
\hline Age & .03 & .71 \\
\hline Years of education & -.17 & .05 \\
\hline Number of chronic illnesses & .04 & .64 \\
\hline Median household income & -.17 & .04 \\
\hline Missed appointments & .41 & $<.001$ \\
\hline Dichotomous variables & Number of ED visits, $M(\mathrm{SD})$ & $p$ \\
\hline \multicolumn{3}{|l|}{ Gender } \\
\hline Male & $0.64(1.00)$ & \multirow[t]{2}{*}{.11} \\
\hline Female & $1.03(1.61)$ & \\
\hline \multicolumn{3}{|l|}{ Race } \\
\hline White & $0.91(1.48)$ & \multirow[t]{2}{*}{.97} \\
\hline Black & $0.89(1.44)$ & \\
\hline \multicolumn{3}{|l|}{ Reading ability } \\
\hline$<9$ th grade & $1.03(1.30)$ & \multirow[t]{2}{*}{.78} \\
\hline At least 9 th grade & $0.94(1.58)$ & \\
\hline \multicolumn{3}{|l|}{ Health numeracy } \\
\hline$<4$ items correct & $1.19(1.75)$ & \multirow[t]{2}{*}{.04} \\
\hline All items correct & $0.66(1.11)$ & \\
\hline \multicolumn{3}{|l|}{ Depression } \\
\hline No depression & $0.66(1.08)$ & \multirow[t]{2}{*}{.02} \\
\hline Probable depression & $1.25(1.76)$ & \\
\hline \multicolumn{3}{|l|}{ Anxiety } \\
\hline No anxiety & $0.93(1.33)$ & \multirow[t]{2}{*}{.91} \\
\hline Probable anxiety & $0.96(1.53)$ & \\
\hline \multicolumn{3}{|l|}{ Cognitive functioning } \\
\hline Normal & $0.61(1.71)$ & \multirow[t]{2}{*}{.02} \\
\hline Probable impairment & $1.15(1.71)$ & \\
\hline \multicolumn{3}{|l|}{ Insurance type } \\
\hline Private & $0.42(0.90)$ & \multirow[t]{2}{*}{$<.001$} \\
\hline Government & $1.31(1.69)$ & \\
\hline
\end{tabular}

Behavioral health consultants, case managers, social workers, and/or nurses could potentially help reduce ER visits by identifying patients at risk for ER visits in primary care. Once patients are identified, providers can attempt to mitigate risk by intervening with these patients, which could include enhancing communication and use of the teach-back method, assisting patients in finding transportation, treating psychiatric diagnoses, or extending business hours. Future work should corroborate our variables and evaluate whether intervening with these patients in a primary care setting can reduce ER utilization.
Table 2 Multivariate Analysis for Variables Predicting Emergency Room Visits

\begin{tabular}{lll}
\hline \hline Variable & Beta & $\boldsymbol{p}$ \\
\hline Health numeracy & -.05 & .60 \\
Depression & .09 & .29 \\
Cognitive functioning & -.08 & .40 \\
Insurance type & .24 & .01 \\
Years of education & .04 & .68 \\
Median household income & -.12 & .15 \\
Missed appointments & .35 & $<.001$ \\
\hline
\end{tabular}

Acknowledgements: A version of this study was presented at the 64th Annual Meeting, Academy of Psychosomatic Medicine in Palm Springs, CA in November 2017.

Corresponding Author: Lisa Renee Miller-Matero, PhD; Department of Behavioral HealthHenry Ford Health System, Detroit, USA (e-mail: Lmatero1@hfhs.org).

\section{Compliance with Ethical Standards:}

Conflict of Interest: The authors declare that they do not have a conflict of interest.

\section{REFERENCES}

1. Krieg C, Hudon C, Chouinard M-C, Dufour I. Individual predictors of frequent emergency department use: a scoping review. BMC health services research. 2016; 16(1):594.

2. Miller-Matero LR, Clark KB, Brescacin C, Dubaybo H, Willens DE. Depression and literacy are important factors for missed appointments. Psychology, health \& medicine. 2016; 21(6):686-95.

3. Nasreddine ZS, Phillips NA, Bédirian V, Charbonneau S, Whitehead V, Collin I, et al. The Montreal Cognitive Assessment, MoCA: a brief screening tool for mild cognitive impairment. Journal of the American Geriatrics Society. 2005; 53(4):695-9.

4. Arozullah AM, Yarnold PR, Bennett CL, Soltysik RC, Wolf MS, Ferreira $\mathbf{R M}$, et al. Development and validation of a short-form, rapid estimate of adult literacy in medicine. Medical care. 2007; 45 (11):1026-33.

5. Miller- Matero LR, Hyde- Nolan ME, Eshelman A, Abouljoud M. Health literacy in patients referred for transplant: do patients have the capacity to understand? Clinical transplantation. 2015; 29(4):336-42.

6. Zigmond AS, Snaith RP. The hospital anxiety and depression scale. Acta psychiatrica scandinavica. 1983; 67(6):361-70. 